\title{
OX40 expression enhances the prognostic significance of CD8 positive lymphocyte infiltration in colorectal cancer
}

\author{
Benjamin Weixler ${ }^{1}$, Eleonora Cremonesi ${ }^{2}$, Roberto Sorge ${ }^{3}$, Manuele Giuseppe \\ Muraro ${ }^{2}$, Tarik Delko ${ }^{1}$, Christian A. Nebiker ${ }^{1}$, Silvio Däster ${ }^{1}$, Valeria Governa ${ }^{2}$, \\ Francesca Amicarella ${ }^{2}$, Savas D. Soysal|, ${ }^{1,2}$, Christoph Kettelhack ${ }^{1}$, Urs W. von \\ Holzen $^{1,4}$, Serenella Eppenberger-Castori ${ }^{5}$, Giulio C. Spagnoli ${ }^{2}$, Daniel Oertli ${ }^{1}$, \\ Giandomenica Iezzi ${ }^{2}$, Luigi Terracciano5 ${ }^{5}$ Luigi Tornillo5, Giuseppe Sconocchia ${ }^{6, *}$ \\ and Raoul A. Droeser ${ }^{1,2, *}$

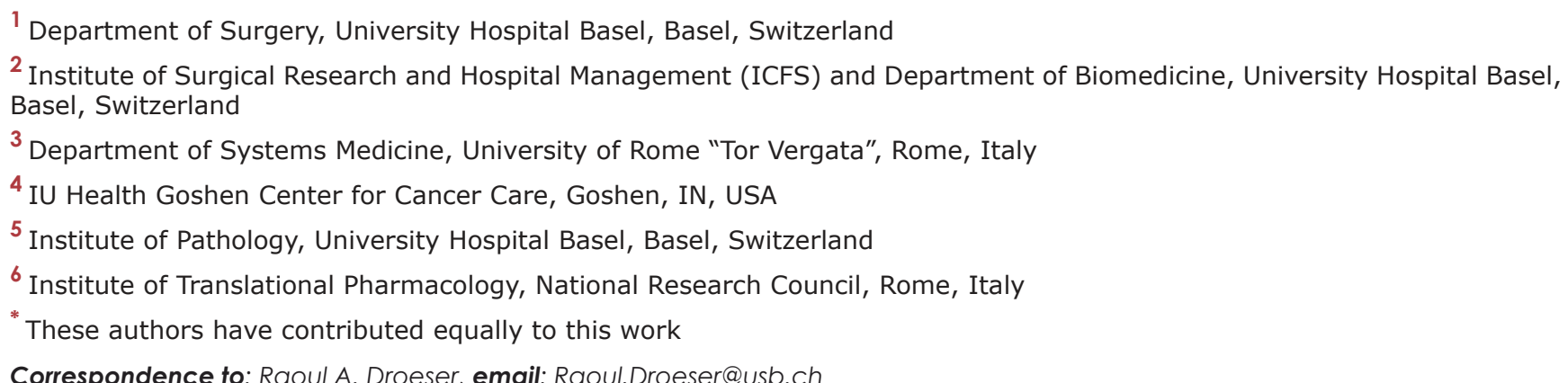 \\ Correspondence to: Raoul A. Droeser, email: Raoul.Droeser@usb.ch
}

Keywords: OX40, CD8, colorectal cancer, prognosis, microenvironment

Received: August 15, $2015 \quad$ Accepted: September 18, $2015 \quad$ Published: September 29, 2015

This is an open-access article distributed under the terms of the Creative Commons Attribution License, which permits unrestricted use, distribution, and reproduction in any medium, provided the original author and source are credited.

\section{ABSTRACT}

Background: OX40 is a TNF receptor family member expressed by activated $T$ cells. Its triggering by $0 \times 40$ ligand promotes lymphocyte survival and memory generation. Anti-0X40 agonistic monoclonal antibodies (mAb) are currently being tested in cancer immunotherapy. We explored the prognostic significance of tumor infiltration by $0 \times 40+$ cells in a large colorectal cancer (CRC) collective.

Methods: OX40 gene expression was analyzed in $\mathbf{5 0}$ freshly excised CRC and corresponding healthy mucosa by qRT-PCR. A tissue microarray including 657 clinically annotated CRC specimens was stained with anti-OX40, -CD8 and -FOXP3 mAbs by standard immunohistochemistry. The CRC cohort was randomly split into training and validation sets. Correlations between CRC infiltration by OX40+ cells alone, or in combination with CD8+ or FOXP3+ cells, and clinical-pathological data and overall survival were comparatively evaluated.

Results: OX40 gene expression in CRC significantly correlated with FOXP3 and CD8 gene expression. High CRC infiltration by $0 \times 40+$ cells was significantly associated with favorable prognosis in training and validation sets in univariate, but not multivariate, Cox regression analysis. CRC with $0 \times 40^{\text {high }} / \mathrm{CD}^{\text {high }}$ infiltration were characterized by significantly prolonged overall survival, as compared to tumors with $0 \times 40^{\text {low }} / C D 8^{\text {high }}$, OX40 $40^{\text {high }} / \mathrm{CD}^{\text {low }}$ or $0 \times 40^{\text {low }} / \mathrm{CD}^{\text {low }}$ infiltration in both uni- and multivariate analysis. In contrast, prognostic significance of OX40+ and FOXP3+ cell infiltration was not enhanced by a combined evaluation. Irrespective of TNM stage, CRC with $0 \times 40^{\text {high }} / \mathrm{CDB}^{\text {high }}$ density infiltrates showed an overall survival similar to that of all stage I CRC included in the study.

Conclusions: $0 \times 40^{\text {high }} / \mathrm{CDB}^{\text {high }}$ density tumor infiltration represents an independent, favorable, prognostic marker in CRC with an overall survival similar to stage I cancers. 


\section{INTRODUCTION}

Colorectal cancer (CRC) represents the second most common cause of cancer-related death [1]. Surgical resection remains the mainstay of CRC therapy, and complete removal of the tumor may be achieved in a majority of patients. Radiotherapy, and chemotherapy represent additional standard treatments, currently administered according to histological findings, using the TNM staging system [2].

Histological staging however, fails to account for recurrences observed in patients treated for early stage $\mathrm{CRC}$ or for long term survival of patients bearing advanced stage CRC [3]. A variety of reports convincingly indicate that the composition of the tumor microenvironment is critical for CRC progression and that the immune system plays a pivotal prognostic role [4-6].

High densities of infiltrating CD8+ $\mathrm{T}$ cells are associated with improved disease-free and overall survival in CRC [4-8] and the analysis of tumor infiltration by immune cells has been suggested to outperform the prognostic significance of TMA staging [5, 6]. Molecular mechanisms underlying the anti-tumor effects of the immune infiltrate are largely unclear $[4,9]$. Nevertheless, the expression of activation markers by CRC infiltrating $\mathrm{CD} 8+\mathrm{T}$ cells has been shown to improve their predictive potential [8]. Unexpectedly, CRC infiltration by FOXP3+ regulatory $\mathrm{T}$ cells (Treg) and myeloid cells was also found to be associated with improved prognosis [1012], at difference with a variety of cancers of different histological origin $[13,14]$.

OX40 (CD134) is a co-stimulatory, trans-membrane molecule of the tumor necrosis factor-receptor superfamily $[15,16]$ expressed by activated CD4+ and CD $8+T$ cells [17-19]. Engagement of OX40 by OX40-ligand expressed by antigen presenting cells (APC) enhances CD4+ and $\mathrm{CD} 8+$ cell proliferation, stimulates cytokine production and promotes survival of antigen-specific memory $\mathrm{T}$ cells [20-22]. Based on this background, OX40 targeted immunotherapy treatments are being tested in patients with advanced cancers [23, 24].

A previous study, based on the analysis of 72 patients with CRC, suggests that OX40 expression by CRC infiltrating cells correlates with favorable prognosis [25]. This information could be of potentially high clinical relevance since it might contribute to the definition of a constellation of markers allowing a more precise identification of patients with CRC who might benefit from current therapies, while sparing unnecessary treatment to others. Furthermore, patients potentially taking advantage of OX40 targeted immunotherapy might also be characterized.

We used a tumor microarray (TMA) including $>600$ clinically annotated CRC to address the prognostic significance of CRC infiltration by OX40+ cells, as evaluated in combination with $\mathrm{CD} 8+$ and FOXP3+ cell infiltration.

RESULTS

\section{OX40 gene expression in CRC and healthy mucosa}

We comparatively addressed OX40 gene expression in CRC tissues and in corresponding healthy mucosa sampled at distance from the tumor $(n=49)$. We found (Figure 1A) that OX40 gene is expressed to similar extents $(P=0.3)$ in cancerous and healthy colon tissues. These results were matched by publicly available data indicating that in five out of seven databases OX40 gene expression did not significantly differ in CRC and healthy tissues [29, 32] (data not shown),

\section{Expression of OX40 gene and genes associated with favorable clinical course in CRC}

Expression of a variety of immune cell markers within CRC tissues has been shown to be associated with defined clinical outcomes [4-6]. Based on this background, we assessed the correlation between OX40 gene expression and that of a panel of genes of known prognostic significance.

In our cohort of CRC tissues $(n=49)$ OX40 gene expression was very strongly (Spearman $\mathrm{r}=0.8, P<$ $0.0001)$ associated with FOXP3 $[10,11]$ gene expression (Figure 1B). Strong associations were also evident between OX40 and IRF1 (Spearman $\mathrm{r}=0.67, P<0.0001$ ) or TBET (Spearman $\mathrm{r}=0.57, P<0.0001$ ) genes $[5,6]$. Furthermore, OX40 gene expression was also moderately associated with CD8 gene expression (Spearman $r=0.33$, $P<0.02$ ). In contrast, no significant associations were detected between OX40 and CD16, IL17A or IFN- $\gamma$ gene expression [12, 37] (Figure 1B). These data were largely consistent with those emerging from TCGA database (Supplementary Figure 1), although in this cohort ( $n$ $=380$ ) OX40 gene expression was also significantly associated with $\mathrm{CD} 16$ and IFN- $\gamma$ gene expression. Taken together these data urged the evaluation of the prognostic significance of OX40+ infiltrate in CRC.

\section{TMA analysis}

A total of 657 CRC tissues were analyzed. Median age was 71 years (range: $36-96$ ), $54.6 \%$ of the patients were female, and $45.4 \%$ were male. $65 \%$ of the tumors were located in the left hemicolon, and the remaining $35 \%$ in the right hemicolon. Median tumor size was 50mm (range: $5-170$ ). Most patients presented T3 lesions $(63.3 \%)$, and $50.7 \%$ were node negative (N0). $85.5 \%$ 
Table 1: Clinical-pathological characteristics of the overall CRC patient cohort and their association with levels of OX40+ infiltrate.

\begin{tabular}{|c|c|c|c|c|c|c|c|}
\hline \multirow[b]{2}{*}{ Characteristics } & \multicolumn{2}{|c|}{$\begin{array}{c}\text { Total } \\
\mathbf{N}=\mathbf{6 5 7}\end{array}$} & \multicolumn{2}{|c|}{$\begin{array}{l}\text { OX40 low } \\
\mathrm{N}=440 *\end{array}$} & \multicolumn{2}{|c|}{$\begin{array}{l}\text { OX40 high } \\
\mathrm{N}=217^{*}\end{array}$} & \multirow{2}{*}{$\begin{array}{c}\text { OX40 } \begin{array}{c}\text { low } \\
\text { high }\end{array} \\
P^{* *} \\
\end{array}$} \\
\hline & $\begin{array}{c}\mathbf{N} \text { or } \\
\text { mean }\end{array}$ & \begin{tabular}{|c|}
$\begin{array}{c}\% \\
\text { range })\end{array}$ \\
\end{tabular} & $\begin{array}{|ll|}\mathbf{N} & \text { or } \\
\text { mean }\end{array}$ & $\begin{array}{c}(\% \text { or } \\
\text { range })\end{array}$ & \begin{tabular}{|l|}
$\mathbf{N}$ or \\
mean
\end{tabular} & \begin{tabular}{|c|}
$(\%$ or \\
range $)$
\end{tabular} & \\
\hline $\begin{array}{l}\text { Age, } \\
\text { mears } \\
\text { mean) }\end{array}$ & $\begin{array}{c}71 \\
69.9\end{array}$ & $(36-96)$ & $\begin{array}{l}72, \\
70.5\end{array}$ & $(36-96)$ & $70,68.6$ & $(40-90)$ & 0.02 \\
\hline $\begin{array}{c}\text { Tumor size in } \mathrm{mm} \\
\text { (median, mean) }\end{array}$ & $\begin{array}{l}50, \\
51.7\end{array}$ & $(5-170)$ & $\begin{array}{l}45, \\
51.5\end{array}$ & $(5-170)$ & $50,50.2$ & $(7-160)$ & 0.827 \\
\hline Sex & & & & & & & 0.539 \\
\hline Female (\%) & 359 & $(54.6)$ & 247 & $(56.1)$ & 112 & $(51.6)$ & \\
\hline Male $(\%)$ & 298 & $(45.4)$ & 193 & $(43.9)$ & 105 & $(48.4)$ & \\
\hline $\begin{array}{c}\text { Anatomic site of the } \\
\text { tumor }\end{array}$ & & & & & & & 0.037 \\
\hline Left-sided (\%) & 425 & $(64.7)$ & 272 & $(61.8)$ & 153 & $(70.5)$ & \\
\hline Right-sided (\%) & 228 & $(34.7)$ & 165 & $(37.5)$ & 63 & $(29.0)$ & \\
\hline & & & & & & & \\
\hline \multicolumn{8}{|l|}{ T stage } \\
\hline T1 (\%) & 29 & $(4.4)$ & 11 & $(2.5)$ & 18 & $(8.3)$ & $<0.0001$ \\
\hline T2 (\%) & 103 & (15.7) & 62 & (14.1) & 41 & (18.9) & \\
\hline T3 (\%) & 416 & (63.3) & 284 & (64.5) & 132 & $(60.8)$ & \\
\hline T4 (\%) & 91 & (13.8) & 74 & $(16.8)$ & 17 & $(7.8)$ & \\
\hline \multicolumn{8}{|l|}{ N stage } \\
\hline N0 (\%) & 333 & $(50.7)$ & 203 & $(46.1)$ & 130 & $(59.9)$ & 0.002 \\
\hline N1 (\%) & 174 & $(26.5)$ & 127 & $(28.9)$ & 47 & $(21.7)$ & \\
\hline $\mathrm{N} 2(\%)$ & 128 & $(19.5)$ & 97 & $(22.0)$ & 31 & $(14.3)$ & \\
\hline Tumor grade & & & & & & & 0.739 \\
\hline G1 (\%) & 15 & $(2.2)$ & 9 & $(2.0)$ & 6 & $(2.8)$ & \\
\hline G2 (\%) & 562 & $(85.5)$ & 377 & $(85.7)$ & 185 & $(85.2)$ & \\
\hline G3 (\%) & 60 & $(9.1)$ & 42 & $(9.6)$ & 18 & $(8.3)$ & \\
\hline \multicolumn{8}{|l|}{ UICC } \\
\hline Stage IA $(\%)$ T1N0 & 21 & $(3.2)$ & 9 & $(2.0)$ & 12 & $(5.5)$ & 0.0003 \\
\hline Stage IB (\%) T2N0 & 73 & $(11.1)$ & 44 & $(10.0)$ & 29 & $(13.4)$ & \\
\hline Stage IIA (\%) T3N0 & 202 & $(30.7)$ & 123 & $(30.0)$ & 79 & $(36.4)$ & \\
\hline Stage IIB-C (\%) T4N0 & 30 & $(4.6)$ & 25 & $(5.7)$ & 5 & $(2.3)$ & \\
\hline Stage III (\%) N+ & 296 & $(45.1)$ & 220 & $(50.0)$ & 76 & $(35.0)$ & \\
\hline \multicolumn{8}{|l|}{$\begin{array}{c}\text { Tumor } \\
\text { configuration }\end{array}$} \\
\hline Infiltrative (\%) & 418 & $(63.6)$ & 285 & $(64.8)$ & 133 & $(61.3)$ & 0.568 \\
\hline Pushing (\%) & 218 & $(33.2)$ & 143 & $(32.5)$ & 75 & $(34.6)$ & \\
\hline \multicolumn{8}{|l|}{ Vascular invasion } \\
\hline No $(\%)$ & 462 & $(70.3)$ & 300 & $(68.2)$ & 162 & $(74.7)$ & 0.044 \\
\hline Yes (\%) & 175 & $(26.6)$ & 129 & $(29.3)$ & 46 & $(21.2)$ & \\
\hline
\end{tabular}




\begin{tabular}{|c|c|c|c|c|c|c|c|}
\hline & & & & & & & \\
\hline Microsatellite Stability & & & & & & & \\
\hline Proficient (\%) & 552 & $(84.0)$ & 362 & $(82.3)$ & 190 & $(87.6)$ & 0.104 \\
\hline Deficient (\%) & 105 & $(16.0)$ & 78 & $(17.7)$ & 27 & $(12.4)$ & \\
\hline Rectal cancers (\%) & 219 & $(33.3)$ & 131 & $(29.8)$ & 88 & $(40.6)$ & 0.013 \\
\hline $\begin{array}{c}\text { Rectosigmoid cancers } \\
\text { (\%) }\end{array}$ & 41 & $(6.2)$ & 33 & $(7.5)$ & 8 & $(3.7)$ & \\
\hline $\begin{array}{c}\text { Median overall survival } \\
\text { time (months) }\end{array}$ & 92 & $0-152$ & 77 & $0-152$ & 101 & $0-150$ & $<0.0001$ \\
\hline $\begin{array}{c}5 \text {-year overall survival \% } \\
\text { (95\%CI) }\end{array}$ & 55.4 & $\begin{array}{c}51.6 \\
59.6\end{array}$ & 49.9 & $\begin{array}{c}45.2 \\
55.1\end{array}$ & 66.1 & $\begin{array}{c}59.9 \\
72.9\end{array}$ & 0.0003 \\
\hline
\end{tabular}

*Percentages may not add to $100 \%$ due to missing values of defined variables.

**Age and tumor size were evaluated using the Mann-Whitney test. Gender, anatomical site, T stage, N stage, grade, vascular invasion, and tumor border configuration were analyzed using the $\chi 2$ or Fisher exact test depending on the number of observations. Survival analysis was performed using the Kaplan-Meier method and comparatively analyzed with the logrank test.

were grade 2 tumors and $61.3 \%$ showed infiltrative tumor border configuration. Vascular invasion was absent in the majority of cases (70\%). TMA included 552 MMRproficient tumors and 105 MMR-deficient tumors (16\%), as defined according to MLH1, MSH2 and MSH6 expression [38]. Median overall survival was of 92 months (0-152) (Table 1). This collective was randomly splitted into two similar training and validation subsets (Table 1s).

\section{Prognostic significance of CRC infiltration by OX40/CD134 cells}

CRC included in the TMA under investigation were infiltrated to different extents by OX40+ cells (Figure 2A). Clinical-pathological characteristics of training and a validation subset did not significantly differ (supplementary Table 1). Cut-off score of OX40+ CRC infiltrating cells for the assessment of their clinical relevance $(n=40)$ was defined by survival ROC curves in the training set (see above). Table 1 shows data related to each clinical-pathological feature, reported as absolute numbers and percentages. Dropouts due to missing information or to loss of punches during TMA staining and preparation represented $<10 \%$ of data.

Kaplan-Meier plots indicate that in both training and validation groups high OX40+ infiltration in CRC is significantly associated with favorable prognosis (Figure 2B). However, the good survival impact of high OX40+ infiltrating cells, failed to reach the threshold of statistical significance in multivariate analysis $(P=0.8)$.

\section{Synergistic prognostic significance of CRC infiltration by OX40+ and CD8+ cells}

OX40 is expressed upon activation by FOXP3+ and $\mathrm{CD} 8+$ human $\mathrm{T}$ cells $[17,39]$. CRC infiltration by cells expressing either marker, known to correlate with favorable clinical course $[5,6,8,10,11]$, was also associated with favorable prognosis in our cohort of patients (data not shown). Importantly, gene expression data support a significant correlation between OX40 and FOXP3 and CD8 gene expression (see above). Therefore, we explored the potentially synergistic prognostic significance of the expression of these markers.

Kaplan-Meier plots revealed that combination of high OX40+ and CD8+ infiltration (Figure 3C) was highly significantly associated with increasingly favorable clinical course, as compared to CRC displaying high $\mathrm{CD} 8+$ but low $\mathrm{OX} 40+$ cell infiltration or CD8+ low but OX40+ high cell infiltration $(P=0.0001)$. In contrast, prognostic significance of $\mathrm{OX} 40+$ cell infiltration in CRC was not significantly improved if data were analyzed in combination with FOXP3+ cell infiltration (Figure 3B). However, poor CRC infiltration by OX40+ and FOXP3+ cells was indeed associated with severe prognosis. These findings were confirmed in the "training" and "validation" subsets (data not shown).

Univariate Cox regression analysis of CRC subgroups identified according to high or low OX40+ and/ or CD8+ infiltration (supplementary Table 2), revealed that $\mathrm{T}$ and $\mathrm{N}$ stage and 5 year overall survival rate where associated with OX40+ and CD8+ density. CRC of pT3-4 or pN1-2 stage did show significantly poorer infiltration by OX40+ and CD8+ cells $(P=0.00005$ and $P=0.00004$, respectively). Mean survival time for patients bearing tumors with OX40+ and CD8+ high, OX40+ low and 
CD8+ high, OX40+ high and CD8+ low and OX40+ low and CD8+ low infiltrate was $53.8( \pm 16.5), 45.7( \pm 21.4)$, $43.2( \pm 21.3)$ and $38.6( \pm 22.5)$ months, respectively. Five year overall survival rate was $82 \%$ (CI: 72-94\%) for patients presenting with high OX40+ and CD8+ tumor infiltration, and 48\% (CI: 43-54\%) for patients bearing tumors with poor OX40+ and CD8+ density $(P=0.0001)$.

Multivariate Hazard Cox regression survival analysis revealed that the combination of high density $\mathrm{OX} 40+$ and $\mathrm{CD} 8+$ cell infiltration $(\mathrm{HR}=0.95 ; 95 \% \mathrm{CI}$
$=93-97 ; P=0.006)$ represents an independent positive prognostic factor for overall survival in CRC. Age (HR = $1.03 ; 95 \% \mathrm{CI}=1.01-1.04 ; P<0.00001)$, gender $(\mathrm{HR}=.65$; $95 \% \mathrm{CI}=.53-.77 ; P=0.0003), \mathrm{T}$-stage $(\mathrm{HR}=1.94 ; 95 \% \mathrm{CI}$ $=1.82-2.05 ; P<0.00001), \mathrm{N}$-stage $(\mathrm{HR}=1.88 ; 95 \% \mathrm{CI}$ $=1.80-1.97 ; P<0.00001)$ and microsatellite instability $(\mathrm{HR}=1.82 ; 95 \% \mathrm{CI}=1.64-2.01 ; P=0.001)$ were also independently associated with favorable prognosis in multivariate survival analysis (Table 2).

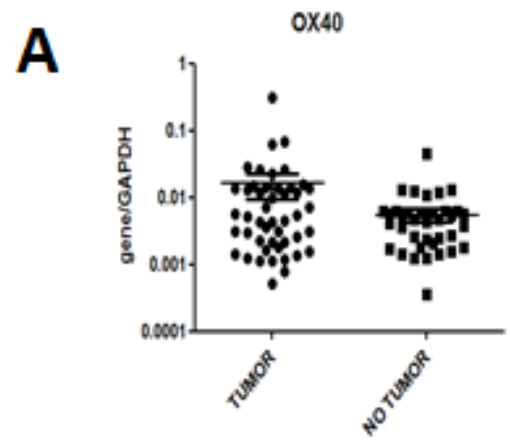

B
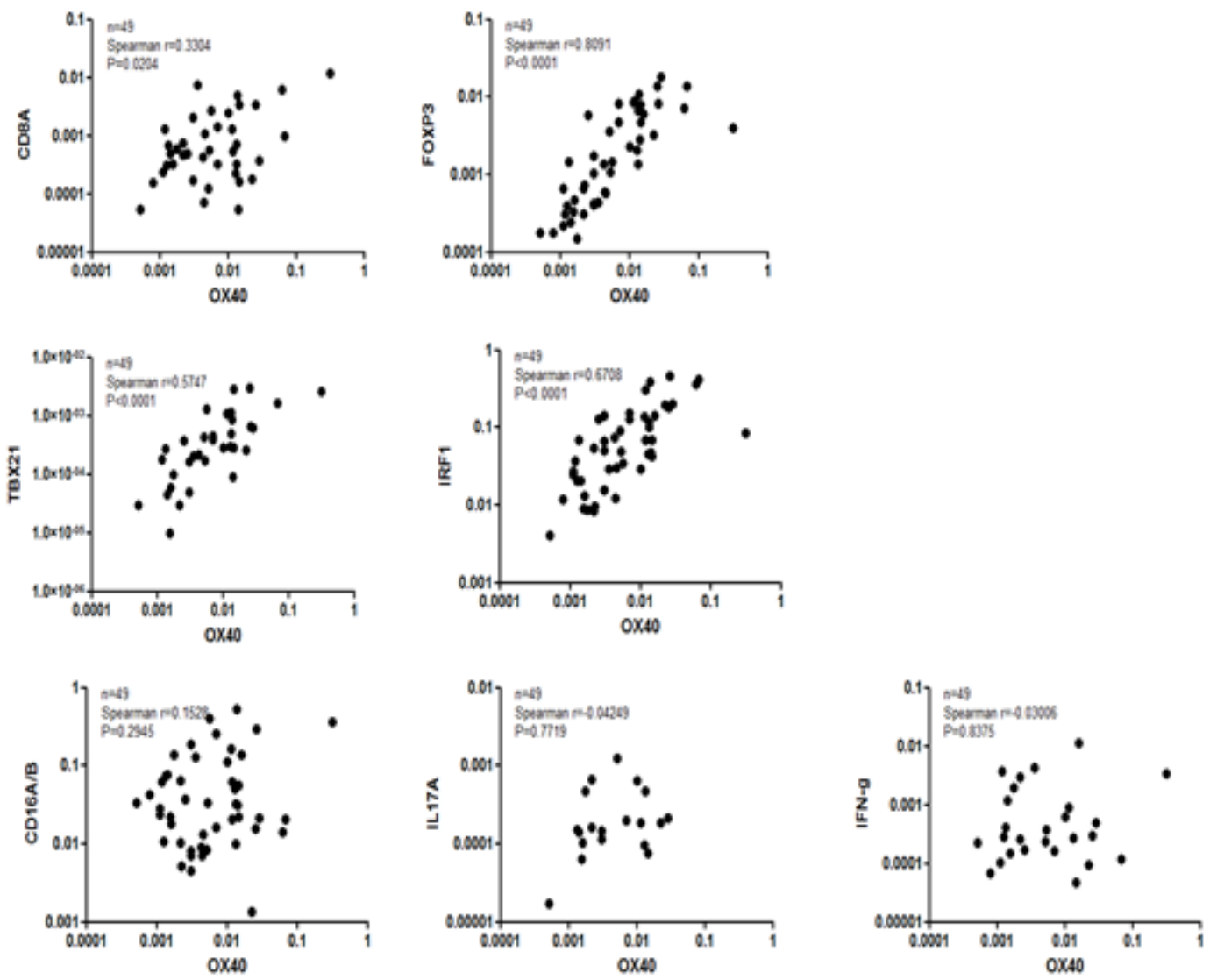

Figure 1: Gene expression profiles in CRC. Total cellular RNA was extracted from freshly excised CRC tissues $(n=48)$ and corresponding healthy mucosa sampled at distance from the tumor and reverse transcribed. Specific gene expression was analyzed by qRTPCR, using, as reference, GAPDH house-keeping gene expression. 
Table 2: Uni and Multivariate Hazard Cox regression survival analysis

\begin{tabular}{|c|c|c|c|c|c|c|}
\hline & \multicolumn{3}{|c|}{ Univariate } & \multicolumn{3}{c|}{ Multivariate } \\
\hline & HR & $\mathbf{9 5 \%}$ CI & p-values & HR & $\mathbf{9 5 \%}$ CI & $p$-values \\
\hline OX40 (continuous) & 0.99 & $0.99-0.99$ & $<0.0001$ & n.i. & & \\
\hline CD8 (continuous) & 0.99 & $0.98-0.99$ & 0.007 & n.i. & & \\
\hline FoxP3 (continuous) & 0.88 & $0.81-0.94$ & 0.049 & n.i. & & \\
\hline OX40 high/low & 0.63 & $0.51-0.75$ & 0.0001 & n.i. & & \\
\hline CD8 high/low & 0.54 & $0.37-0.70$ & 0.0002 & n.i. & & \\
\hline OX40 high CD8 $^{\text {high }}$ & 0.93 & $0.92-0.95$ & $<0.0001$ & 0.95 & $0.93-0.97$ & 0.006 \\
\hline FoxP3 high/ow & 0.77 & $0.66-0.88$ & 0.02 & 0.84 & $0.72-096$ & 0.15 \\
\hline Age & 1.02 & $1.01-1.03$ & 0.0001 & 1.03 & $1.02-1.04$ & $<0.00001$ \\
\hline Gender (men vs women) & 0.67 & $0.67-0.67$ & 0.0002 & 0.65 & $0.53-0.77$ & 0.0003 \\
\hline pT stage & 2.25 & $2.16-2.34$ & $<0.000001$ & 1.94 & $1.82-2.05$ & $<0.00001$ \\
\hline Tumor grade & 1.51 & $1.36-1.67$ & 0.008 & 1.22 & $1.03-1.41$ & 0.28 \\
\hline pN stage & 2.28 & $2.21-2.35$ & $<0.000001$ & 1.88 & $1.80-1.97$ & $<0.00001$ \\
\hline Vascular invasion & 2.46 & $2.35-2.58$ & $<0.000001$ & 1.48 & $1.35-1.62$ & 0.004 \\
\hline Tumor border configuration & 2.03 & $1.90-2.16$ & $<0.000001$ & 1.39 & $1.24-1.54$ & 0.029 \\
\hline $\begin{array}{c}\text { Microsatellite stability (deficient } \\
\text { vs. proficient) }\end{array}$ & 1.55 & $1.38-1.72$ & 0.01 & 1.82 & $1.64-2.01$ & \multirow{2}{*}{0.001} \\
\hline
\end{tabular}

Uni- and multivariate Cox-regression analyses showing Hazard Ratios and P-values.

The multivariate model included 556 patients, due to missing values related to CD8+ and FOXP3+ density, age, sex, tumor size, tumor grade, vascular invasion, tumor border configuration and microsatellite stability. n.i.: not included in the final multivariate model.
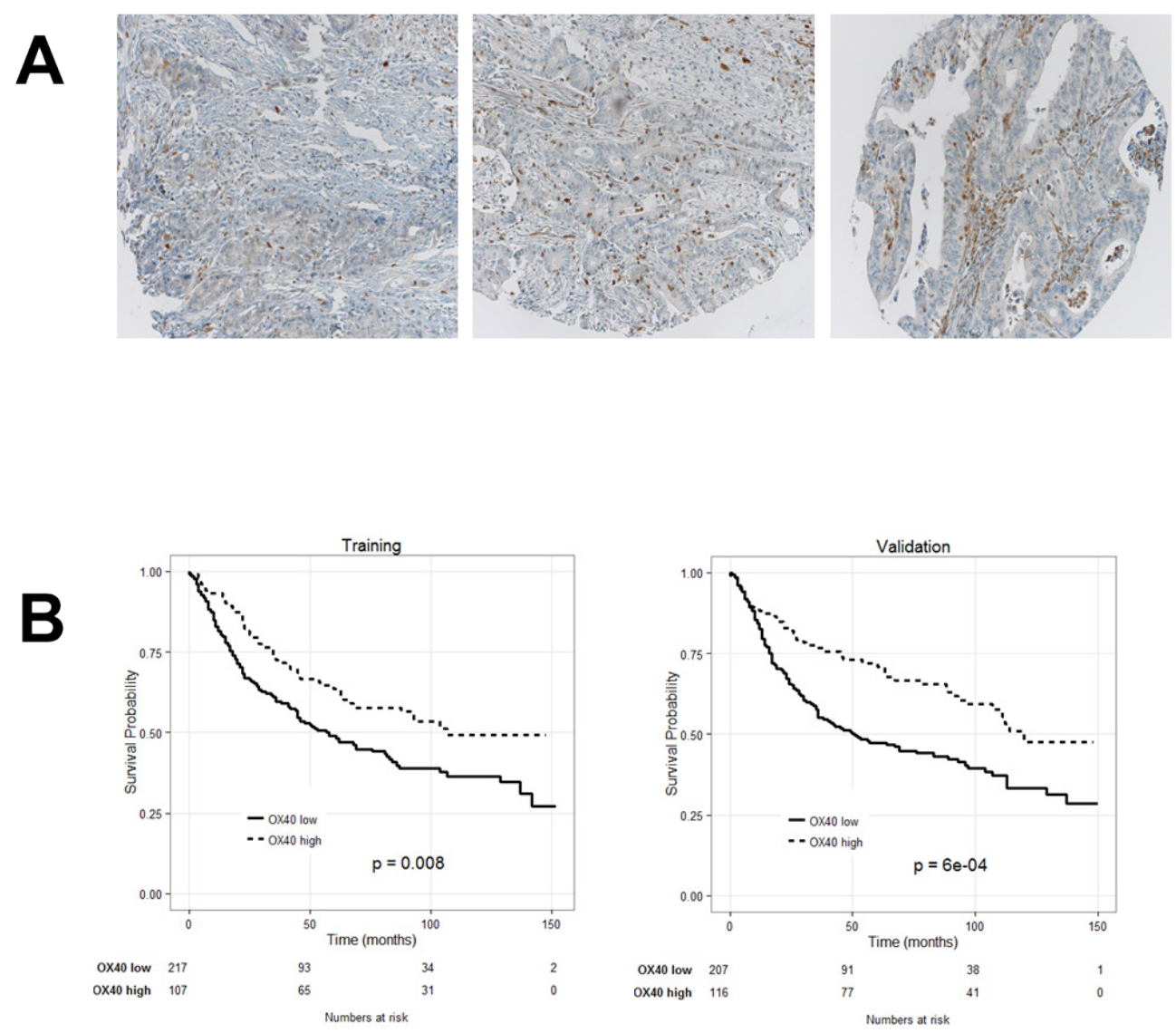

Figure 2: Prognostic significance of OX40 expression by CRC infiltrating cells. A. CRC TMA was stained with OX40 specific reagents, as detailed in "materials and methods". Panel A.shows representative punches with different extents of OX40+ cell infiltration (magnification 20X).Kaplan-Meier plots depicting the prognostic significance in randomly generated training and validation cohorts (panel B.). Number of events ( = deaths) and total number of cases in each cohort are reported. 

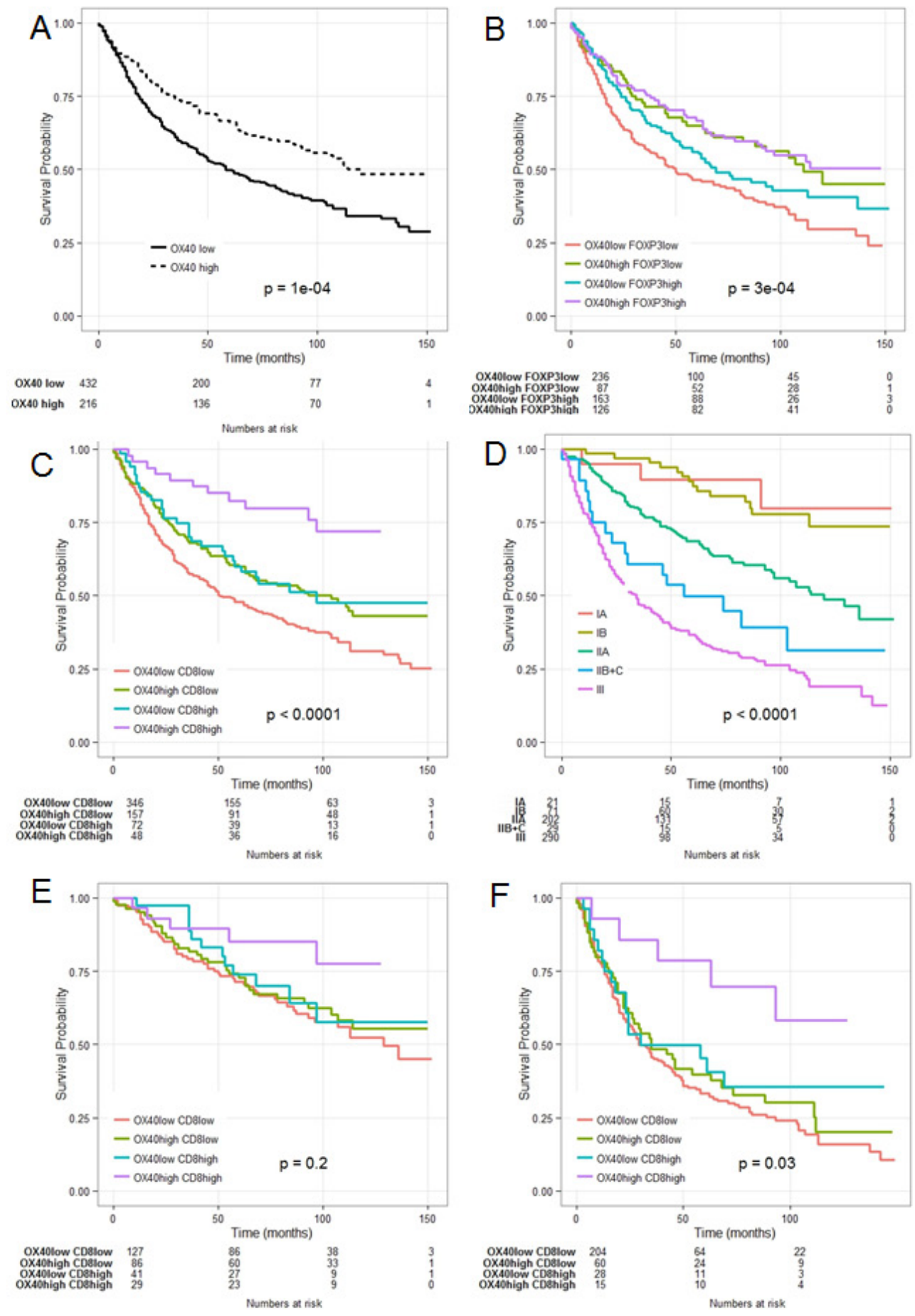

Figure 3: Combined Kaplan- Meier analysis of OX40+ and CD8+ infiltration results in enhanced prognostic significance in CRC. OX40+ in the overall collective (panel A.); OX40+ combined with FOXP3+ (panel B.); OX40+ combined with CD8+ cell infiltration (panel C.); comparative evaluation with conventional TNM staging (panel D.); OX40+/CD8+ in low stage CRC(panel E.) and in high grade (panel F.). 


\section{Comparative analysis of the prognostic significance of $\mathrm{OX} 40+$ and CD8+ infiltration and AJCC staging}

Previous studies suggest that infiltration by immune cells might outperform conventional tumor staging in CRC prognostic assessment (4). Therefore, we comparatively evaluated the prognostic significance of $\mathrm{OX} 40+$ and CD8+ infiltration and AJCC staging (Figure 3 panel C, D). Survival probability at five years was $85.2 \%$ (C.I. 72.6\%-99.9\%) for patients with low (IA, IB and IIA) AJCC stage and $78.6 \%$ (C.I. $59.8 \%-100 \%$ ) for patients with high stage (IIB, IIC and III) (Figure 3, panel E, F). Prognostic impact of OX40/CD8 high density infiltration did not reach significance threshold $(P=0.2)$ for patients with low stages, since the overall survival in this cohort is inherently good and analysis of a larger number of patients would be required. However, of peculiar clinical importance is the significant $(P=0.03)$ favorable prognostic impact of high density OX40+ and CD8+ cell infiltration in high AJCC stage CRC. Thus, irrespective of their AJCC staging, CRC highly infiltrated by OX40+ and $\mathrm{CD} 8+$ cells are characterized by a prognosis similar to that of stage I patients CRC (Figure 3, panel C-F).

\section{DISCUSSION}

Experimental models show that signaling through OX40 co-stimulatory molecule promotes the generation of $\mathrm{T}$ cell memory thereby significantly enhancing antigen specific re-call responses [22, 40]. Furthermore, administration of agonistic OX40 specific mAbs enhances anti-tumor immune responses "in vivo" in different models [41]. Responsiveness to treatment is accompanied by increasing densities of OX40+ CD8 $+\mathrm{T}$ cells within the tumor tissue and decreasing FOXP3+ Treg infiltration [24]. Based on this background, similar reagents are currently being tested in clinical immunotherapy trials $[23,42]$.

Although analysis of CRC immune-contexture is increasingly gaining clinical relevance [4-6], prognostic significance of OX40 expression in CRC infiltrating cells has only been explored in one study evaluating a cohort of 72 patients [25].

Here, we report that in CRC OX40 gene expression is significantly correlated to that of $\mathrm{CD} 8, \mathrm{FOXP} 3$, TBET and IRF1 genes, typically expressed in tumors with favorable prognosis $[5,6]$.

Indeed, the analysis of $>600$ clinically annotated CRC specimens indicates that $\mathrm{OX} 40+$ cell infiltration is significantly associated with increased overall survival, although this favorable prognostic effect could not be confirmed in multivariate analysis.

Most importantly however, a combined evaluation shows for the first time that CRC infiltration by high density OX40+ and CD8+ cells is highly significantly associated with favorable clinical course, as also evident upon multivariate analysis. Strikingly, CRC with high OX40+ and CD8+ cell infiltration, irrespective of their TNM stage, are characterized by a prognosis similar to that of low (IA-IB) stage cancers within the whole cohort under investigation.

In contrast, interestingly, no such effects were observed upon combined analysis of both $\mathrm{OX} 40+$ and FOXP3+ cell CRC infiltration.

These data do not provide obvious mechanistic insights. However, it has been shown in "in vivo" models that effects of OX40 triggering are enhanced in the presence of "danger" signals [22]. Indeed, CRC carcinogenesis is typically characterized by early loss of the barrier function of intestinal mucosa [43]. Thus, a variety of TLR agonists might provide adequate "danger" signals potentially supporting the induction of antitumor effects associated with OX40 stimulation.

Besides activated $\mathrm{T}$ lymphocytes, OX40 expression has also been observed in natural killer $\mathrm{T}$ cells and neutrophils [17]. However, in our gene expression studies we did not observe a significant correlation between expression of OX40 and expression of CD16 gene, typically detectable in these cell types.

Our study has limitations, including its retrospective nature. However, data emerging from large retrospective analyses may help in the development of targeted prospective studies, currently being planned by our groups. Furthermore, the cohort investigated in this study includes patients bearing CRC surgically treated between 1985 and 1998, e.g. prior to a widespread use of neoadjuvant treatment regimens. Therefore, although our results may not be fully representative of current clinical treatment, they are more likely to faithfully mirror CRC immunobiology, in the absence of chemo-irradiation treatments.

On the other hand, TMA technology may insufficiently represent tumor tissue heterogeneity. However, punches included in the TMA under investigation are derived from the tumor center and do include at least $50 \%$ cancer cells. Furthermore, the number of CRC considered (>600) is likely to compensate at least in part for the diversity of immune contexture within different areas of individual biopsies.

Nevertheless, our data indicate that OX40 and CD8 specific staining may outperform TNM staging, thus potentially contributing to clinical decision making in sizeable groups of patients. On the other hand, they underline the critical relevance of OX40 in CRC immunobiology. Further research is warranted to unravel underlying molecular mechanisms. 


\section{MATERIALS AND METHODS}

\section{Gene expression analysis}

Total cellular RNA was extracted from surgical specimens of CRC and autologous healthy mucosa (HM) sampled at distance from the tumor and reverse transcribed [26]. Pre-developed Taqman ${ }^{\circledR}$ assays (Applied Biosystems) were used to quantitatively evaluate the expression of a panel of cytokine and chemokine genes by using ABI Prism 7300 PCR system (Applied Biosystems). Data are reported as relative expression normalized to GAPDH house-keeping gene amplification. Expression of individual genes was analyzed by using the $2^{-\Delta \Delta c}{ }_{T}$ method [27].

\section{Public databases}

Gene expression databases included in Oncomine databank [28] were used to analyze OX40 gene expression in CRC in comparison with normal tissues. Seven databases, including a total of 812 samples, were identified. Skrzypczak [29], Hong [30] and Kaiser [31] databases utilized Human Genome U133 Plus 2.0 technology (Affymetrix), whereas Gaedcke [32] used Agilent platform. Instead, TCGA data were obtained by using next generation sequencing (NGS) technology and Ki [33] data are based on a not pre-defined platform.

\section{Tissue microarray construction}

657 unselected, non-consecutive, clinically annotated, primary CRC specimens were included in the TMA following approval by the Regional Ethical Committee (EKBB, Basel Stadt and Basel Land). Formalin-fixed, paraffin-embedded tissue blocks were prepared according to standard procedures. Tissue cylinders with a diameter of $0.6 \mathrm{~mm}$ were punched from morphologically representative areas of each donor block and brought into one recipient paraffin block $(30 \times 25 \mathrm{~mm})$, using a semi-automated tissue arrayer. Each punch was made from the center of the tumor so that each TMA spot consisted of at least $50 \%$ tumor cells.

\section{Clinical-pathological features}

Clinical-pathological data for the patients included in the TMA are listed in Table 1. Briefly, data were collected retrospectively in a non-stratified and nonmatched manner. Annotation included patient age, tumor diameter, location, $\mathrm{pT} / \mathrm{pN}$ stage, grade, histologic subtype, vascular invasion, border configuration, presence of peritumoral lymphocytic inflammation at the invasive tumor front and disease-specific survival. Tumor border configuration and peritumoral lymphocytic inflammation were evaluated using the original H\&E slides of the resection specimens corresponding to each tissue microarray punch [34].

\section{Immunohistochemistry}

Standard indirect immunoperoxidase procedures were used for immunohistochemistry (IHC; ABC-Elite, Vector Laboratories, Burlingame, CA). Slides were dewaxed and rehydrated in distilled water. Endogenous peroxidase activity was blocked using $0.5 \% \mathrm{H} 2 \mathrm{O} 2$. Sections were incubated with $10 \%$ normal goat serum (DakoCytomation, Carpinteria, CA) for $20 \mathrm{~min}$ and incubated with primary antibody at room temperature. Primary antibodies used were specific for OX40 (polyclonal anti-CD134/OX40, ab119904, Abcam, Cambridge, UK), CD8 (clone C8/144B, DakoCytomation, Switzerland) and FOXP3 (clone 236A/E7, Abcam, Cambridge, UK) [7, 10]. Subsequently, sections were incubated with peroxidase-labelled secondary antibody (DakoCytomation) for $30 \mathrm{~min}$ at room temperature. To visualize the antigen, sections were immersed in 3-amino-9-ethylcarbazole plus substrate-chromogen (DakoCytomation) for $30 \mathrm{~min}$, and counterstained with Gill's hematoxylin.

\section{Evaluation of immunohistochemistry}

Immunohistochemical readings were performed by trained research fellows [B.W. or R.D.] and data were independently validated by an additional investigator [L.To.]. Tumor infiltrating cells were counted for each punch (approximately one high power [20x] field). Data regarding CRC infiltration by FOXP3+ and CD8+ were available from our previous publications $[7,8,10]$.

\section{Statistical analysis}

Data were analyzed using the Statistical Package Software R (Version 3.1.3, www.r-project.org). Following confirmation histogram and the Kolgomorov-Smirnov test, descriptive statistic included mean \pm standard deviation for parameters with Gaussian distribution or percentage of frequencies for occurrences.

The TMA collective of 657 CRC was randomly split into training and validation subsets with approximately equal numbers of patients $(n=329$ and $n=328$, respectively). Associations with survival were explored using the Cox proportional hazards regression model. Cutoff values used to classify CRC with low or high immune cell infiltration were obtained by ROC curves (survival ROC package), evaluating sensitivity and false positive 
rate for the discrimination of survivors and non-survivors with respect to the Kaplan-Meier method, on the training subset and validated on the validation subset $[35,36]$. The threshold value for OX40+ infiltration, calculated in the training test was 40 cells/TMA-punch. This value was reconfirmed in the validation set. Further specific scores were set at 10 cells/TMA-punch for CD8 and 17 cells/ TMA-punch for FOXP3, as previously calculated in larger collectives by our team $[8,10]$.

Chi-Square, Fisher's Exact, and Kruskal-Wallis tests were used to determine the association of $\mathrm{OX} 40+$ and CD8+ infiltration and clinical-pathological features. Univariate survival analysis was performed by the Kaplan-Meier method and log rank test. The assumption of proportional hazards was verified for all markers by analyzing correlation of Schoenfeld residuals and ranks of individual failure times. Any missing clinical-pathological information was assumed to be missing at random. Subsequently, OX40, CD8, and FOXP3 cell infiltration data were entered into multivariate Cox regression analysis and hazard ratios (HR) and 95\% confidence intervals (CI) were used to determine prognostic effects on survival time. $P$-values $<0.05$ were considered statistically significant.

\section{SOURCES OF FINANCIAL SUPPORT}

GS was supported by the Italian Association for Cancer Research (AIRC), grant 10555 and PRIN, the Ministry of Education, University and Research (PRIN), grant 2010AX2JX7_005. GI was supported by SNF (CH) grant no. PP00P3-133699. GCS was supported by SNF (CH) grant no. 310030_149745.

\section{ACKNOWLEDGEMENTS}

All authors have agreed to the submission of this manuscript and have participated in the study to a sufficient extent to be named as authors. The authors have no conflicts of interest to disclose for the present study.

\section{CONFLICTS OF INTEREST}

There is no conflict of interest.

\section{REFERENCES}

1. Ferlay J, Soerjomataram I I, Dikshit R, Eser S, Mathers C, Rebelo M, Parkin D M, Forman D D, Bray F. Cancer incidence and mortality worldwide: sources, methods and major patterns in GLOBOCAN 2012. Int J Cancer 2014;136:E359-86.

2. Cunningham D, Atkin W, Lenz H-J, Lynch HT, Minsky B, Nordlinger B, Starling N. Colorectal cancer. Lancet (London, England) 2010;375:1030-47.

3. Zlobec I, Lugli A. Prognostic and predictive factors in colorectal cancer. Postgrad Med J 2008;84:403-11.

4. Fridman WH, Pagès F, Sautès-Fridman C, Galon J. The immune contexture in human tumours: impact on clinical outcome. Nat Rev Cancer 2012;12:298-306.

5. Galon J, Costes A, Sanchez-Cabo F, Kirilovsky A, Mlecnik $B$, Lagorce-Pagès $C$, Tosolini $M$, Camus $M$, Berger A, Wind $\mathrm{P}$, Zinzindohoué F, Bruneval $\mathrm{P}$, Cugnenc $\mathrm{PH}$, et al. Type, density, and location of immune cells within human colorectal tumors predict clinical outcome. Science 2006;313:1960-4.

6. Pagès F, Berger A, Camus M, Sanchez-Cabo F, Costes A, Molidor R, Mlecnik B, Kirilowsky A, Nilsson M, Damotte D, Meatchi T, Brunveal P, Cugnenc PH, et al. Effector memory $\mathrm{T}$ cells, early metastasis, and survival in colorectal cancer. N Engl J Med 2005;353:2654-66.

7. Lugli A, Karamitopoulou E, Panayiotides I, Karakitsos P, Rallis G, Peros G, Iezzi G, Spagnoli G, Bihl M, Terracciano L, Zlobec I. CD8+ lymphocytes/ tumour-budding index: an independent prognostic factor representing a "pro-/antitumour" approach to tumour host interaction in colorectal cancer. Br J Cancer 2009;101:1382-92.

8. Zlobec I, Karamitopoulou E, Terracciano L, Piscuoglio S, Iezzi G, Muraro MG, Spagnoli G, Baker K, Tzankow A, Lugli A. TIA-1 cytotoxic granule-associated RNA binding protein improves the prognostic performance of CD8 in mismatch repair-proficient colorectal cancer. PLoS One 2010;5:e14282.

9. Reissfelder C, Stamova S, Gossmann C, Braun M, Bonertz A, Walliczek U, Grimm M, Rahbari N, Koch M, Saadati M, Benner A, Buechler MW, Jaeger D, et al. Tumor-specific cytotoxic $\mathrm{T}$ lymphocyte activity determines colorectal cancer patient prognosis. J Clin Invest 2015;125:739-51.

10. Frey DM, Droeser RA, Viehl CT, Zlobec I, Lugli A, Zingg U, Oerlti D, Kettelhack C, Terracciano L, Tornillo L. High frequency of tumor-infiltrating FOXP3 $(+)$ regulatory T cells predicts improved survival in mismatch repair-proficient colorectal cancer patients. Int J Cancer 2010;126:2635-43.

11. Salama P, Phillips M, Grieu F, Morris M, Zeps N, Joseph D, Platell C, Iacopetta B. Tumor-infiltrating FOXP3+ T regulatory cells show strong prognostic significance in colorectal cancer. J Clin Oncol 2009;27:186-92.

12. Sconocchia G, Zlobec I, Lugli A, Calabrese D, Iezzi G, Karamitopoulou E, Patsouris E, Peros G, Horcic M, Tornillo L, Zuber M, Droeser R, Muraro MG, et al. Tumor infiltration by FcyRIII (CD16)+ myeloid cells is associated with improved survival in patients with colorectal carcinoma. Int J Cancer 2011;128:2663-72.

13. Condeelis J, Pollard JW. Macrophages: obligate partners for tumor cell migration, invasion, and metastasis. Cell 2006;124:263-6.

14. Curiel TJ. Tregs and rethinking cancer immunotherapy. J Clin Invest 2007;117:1167-74.

15. Gough MJ, Weinberg AD. OX40 (CD134) and OX40L. Adv Exp Med Biol 2009;647:94-107. 
16. Taraban VY, Rowley TF, O’Brien L, Chan HTC, Haswell LE, Green MHA, Tutt AL, Glennie MJ, Al-Shamkhani A. Expression and costimulatory effects of the TNF receptor superfamily members CD134 (OX40) and CD137 (4-1BB), and their role in the generation of anti-tumor immune responses. Eur J Immunol 2002;32:3617-27.

17. Croft M. Control of immunity by the TNFR-related molecule OX40 (CD134). Annu Rev Immunol 2010;28:5778.

18. Sugamura K, Ishii N, Weinberg AD. Therapeutic targeting of the effector T-cell co-stimulatory molecule OX40. Nat Rev Immunol 2004;4:420-31.

19. Weinberg AD, Evans DE, Thalhofer C, Shi T, Prell RA. The generation of $\mathrm{T}$ cell memory : a review describing the molecular and cellular events following OX40 ( CD134 ) engagement 2004;40.

20. Bansal-Pakala P, Halteman BS, Cheng MH-Y, Croft M. Costimulation of CD8 T cell responses by OX40. J Immunol 2004;172:4821-5.

21. De Smedt T, Smith J, Baum P, Fanslow W, Butz E, Maliszewski C. Ox40 costimulation enhances the development of $\mathrm{T}$ cell responses induced by dendritic cells in vivo. J Immunol 2002;168:661-70.

22. Maxwell JR, Weinberg A, Prell RA, Vella AT. Danger and OX40 receptor signaling synergize to enhance memory $\mathrm{T}$ cell survival by inhibiting peripheral deletion. J Immunol 2000;164:107-12.

23. Curti BD, Kovacsovics-Bankowski M, Morris N, Walker E, Chisholm L, Floyd K, Walker J, Gonzalez I, Meeuwsen T, Fox B, Moudgil T, Miller W, Haley D, et al. OX40 is a potent immune-stimulating target in late-stage cancer patients. Cancer Res 2013;73:7189-98.

24. Gough MJ, Ruby CE, Redmond WL, Dhungel B, Brown A, Weinberg AD. OX40 agonist therapy enhances CD8 infiltration and decreases immune suppression in the tumor. Cancer Res 2008;68:5206-15.

25. Petty JK, D M, He K, Corless CL, Ph D, Vetto JT, Weinberg AD. Survival in human colorectal cancer correlates with expression of the T-cell costimulatory molecule OX-40 ( CD134 ) 2002;183:512-8.

26. Nebiker CA, Han J, Eppenberger-Castori S, Iezzi G, Hirt C, Amicarella F, Cremonesi E, Huber X, Padovan E, Angrisani B, Droeser R, Rosso R, Bolli M, et al. GM-CSF Production by Tumor Cells Is Associated with Improved Survival in Colorectal Cancer. Clin Cancer Res 2014;20:3094-106.

27. Livak KJ, Schmittgen TD. Analysis of relative gene expression data using real-time quantitative PCR and the 2(-Delta Delta C(T)) Method. Methods 2001;25:402-8.

28. Rhodes DR, Yu J, Shanker K, Deshpande N, Varambally R, Ghosh D, Barrette T, Pandey A, Chinnaiyan AM. ONCOMINE: a cancer microarray database and integrated data-mining platform. Neoplasia 6:1-6.

29. Skrzypczak M, Goryca K, Rubel T, Paziewska A, Mikula M, Jarosz D, Pachlewski J, Oledzki J, Ostrowski J,
Ostrowsk J, et al. Modeling oncogenic signaling in colon tumors by multidirectional analyses of microarray data directed for maximization of analytical reliability. PLoS One 2010;5.

30. Hong Y, Downey T, Eu KW, Koh PK, Cheah PY. A "metastasis-prone" signature for early-stage mismatchrepair proficient sporadic colorectal cancer patients and its implications for possible therapeutics. Clin Exp Metastasis 2010;27:83-90.

31. Kaiser S, Park Y-K, Franklin JL, Halberg RB, Yu M, Jessen WJ, Freudenberg J, Chen X, Haigis K, Jegga AG, Kong S, Sakthivel B, Xu H, Reichling T, et al. Transcriptional recapitulation and subversion of embryonic colon development by mouse colon tumor models and human colon cancer. Genome Biol 2007;8:R131.

32. Gaedcke J, Grade M, Jung K, Camps J, Jo P, Emons G, Gehoff A, Sax U, Schirmer M, Becker H, Beissbarth T, Ried T, Ghadimi BM. Mutated KRAS results in overexpression of DUSP4, a MAP-kinase phosphatase, and SMYD3, a histone methyltransferase, in rectal carcinomas. Genes Chromosomes Cancer 2010;49:1024-34.

33. Ki DH, Jeung H-C, Park CH, Kang SH, Lee GY, Lee WS, Kim NK, Chung HC, Rha SJ. Whole genome analysis for liver metastasis gene signatures in colorectal cancer. Int $\mathbf{J}$ Cancer 2007;121:2005-12.

34. Jass JR, Atkin WS, Cuzick J, Bussey HJ, Morson BC, Northover JM, Todd IP. The grading of rectal cancer: historical perspectives and a multivariate analysis of 447 cases. Histopathology 1986;10:437-59.

35. Blanche P, Dartigues J-F, Jacqmin-Gadda H. Estimating and comparing time-dependent areas under receiver operating characteristic curves for censored event times with competing risks. Stat Med 2013;32:5381-97.

36. Zlobec I, Steele R, Terracciano L, Jass JR, Lugli A. Selecting immunohistochemical cut-off scores for novel biomarkers of progression and survival in colorectal cancer. J Clin Pathol 2007;60:1112-6.

37. Tosolini M, Kirilovsky A, Mlecnik B, Fredriksen T, Mauger S, Bindea G, Berger A, Bruneval P, Fridman WH, Pages F, Galon J. Clinical Impact of Different Classes of Infiltrating T Cytotoxic and Helper Cells (Th1, Th2, Treg, Th17) in Patients with Colorectal Cancer. Cancer Res 2011;71:126371.

38. Hampel H, Stephens JA, Pukkala E, Sankila R, Aaltonen LA, Mecklin J-P, de la Chapelle A. Cancer risk in hereditary nonpolyposis colorectal cancer syndrome: later age of onset. Gastroenterology 2005;129:415-21.

39. Piconese S, Timperi E, Pacella I, Schinzari V, Tripodo C, Rossi M, Guglielmo N, Mennini G, Grazi GL, Di Filippo S, Brozzetti S, Fazzi K, Antonelli G, et al. Human OX40 tunes the function of regulatory $\mathrm{T}$ cells in tumor and nontumor areas of hepatitis C virus-infected liver tissue. Hepatology 2014;60:1494-507. 
40. Ruby CE, Redmond WL, Haley D, Weinberg AD. AntiOX40 stimulation in vivo enhances CD8 + memory $\mathrm{T}$ cell survival and significantly increases recall responses 2007:157-66.

41. Weinberg a D, Rivera MM, Prell R, Morris a, Ramstad T, Vetto JT, Urba WJ, Alvord G, Bunce C, Shields J. Engagement of the OX-40 receptor in vivo enhances antitumor immunity. J Immunol 2000;164:2160-9.

42. Weinberg AD, Morris NP, Kovacsovics-Bankowski M, Urba WJ, Curti BD. Science gone translational: the OX40 agonist story. Immunol Rev 2011;244:218-31.

43. Abreu MT. Toll-like receptor signalling in the intestinal epithelium: how bacterial recognition shapes intestinal function. Nat Rev Immunol 2010;10:131-44. 